\title{
Vaccine Adjuvants Revisited
}

\author{
Nikolaus A. Grubhofer ${ }^{*}$ \\ Gerbu Biotechnik GmbH, D-69251 Gaiberg, Germany
}

\begin{abstract}
A huge amount of evidence has been made available on various adjuvants as immunological auxiliaries. Very few of them, however, have made it into commercial vaccines. Their defining properties and uses are discussed in the following mini-review.
\end{abstract}

\section{WHAT IS AN ADJUVANT?}

In Freund's words [1] an adjuvant should "evoke very abundant serum antibody production sustained for an unexpectedly long time". In other words, it is something very practical. It must work in animals at least the size of sheep and of course in both veterinary and human vaccination. To this end it must be thoroughly biocompatible, easy to handle and to store, sterile, safe, acceptable for registration as an auxiliary in vaccination and, last but not least, must have an affordable price.

"Abundant serum antibody production" moreover always seems to go hand-in-hand with a host of other beneficial cellular immunostimulatory effects.

\section{WHAT IS NOT AN ADJUVANT?}

The following are not adjuvants: Any soluble or insoluble substance producing antibodies only in mice (which then have to take the blame for "lying"), and also immunopotentiators (showing saturation doses) or immunomodulators (showing dose optimum and even inhibition at the high end). Examples are: water soluble muramyl peptides, saponins, liposaccharides, hormones. These one might characterize as "adjuvants for adjuvants", or, in a word, pseudo-adjuvant. Undoubtedly they are important in special cases, but their usefulness is more remote.

Whether, for instance, the glycopeptide GMDP, a powerful cellular promotor is of any real use in a vaccine unfortunately cannot be established with a few mice but requires field tests with 2000 volunteers. This typifies the vaccine adjuvant dilemma.

\section{ALUMINUM HYDROXIDE GELS}

A.T. Glenny [2] (1926) and his colleagues introduced the notion that the "antigenic value" of a toxoid is higher if it is not in solution, but comes attached to solid particles, and they proposed immunizing with a precipitate of aluminium hydroxide containing adsorbed diphtheria toxin.

Merschheimer [3] introduced preformed, standardized alumina gels which can absorb the protein antigen in a truly industrial process. The first practically usable "Alhydrogel" was delivered to a vaccine manufacturer in 1939.

*Address correspondence to this author at the Gerbu Biotechnik GmbH, D69251 Gaiberg, Germany; E-mail: Gerbu@t-online.de
A long way from Glenny's test tube material were the salts, removed in tonnage level from the alumina precipitate, which, after heat sterilization and $\mathrm{pH}$ adjustment, remained economically priced.

Then was a good time: alumina gels were easy to use and easy to understand, regulatory hurdles were zero. The gels could be put into the vaccine just like a special kind of buffer. So manufacturers liked to use them.

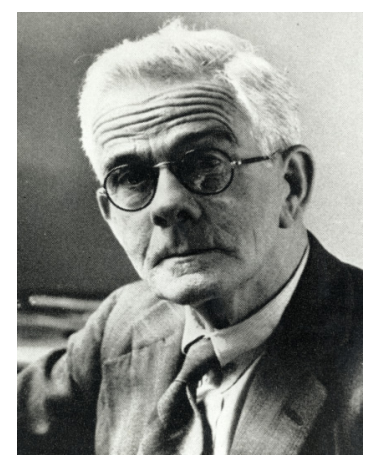

A.T. Glenny

\section{WATER IN OIL EMULSIONS}

Ten years later, Jules Freund at the Public Health Institute of the City of New York entered the field and studied ways to increase the formation of antibodies to tuberculosis, drawing on a wealth of facts established during the preceding 50 years: Lydia Rabinowitsch [4] (1897) had observed that immunisation with Mycobacterium butyricum (similar to M. tuberculosis), gave a greater immune response if injected together with the butter in which it used to occur in those times. Grassberger (1899) [5] showed that paraffin oil worked even better than butter.

In 1948 Freund [6] described his mixture of commercial mineral oil and emulsifiers made into an ointment consisting of antigen solution in the oil. This formulation, and the term "Immunological Adjuvant" which he coined, have immortalized their originator. This was an effective but not very practical adjuvant. Too cumbersome to prepare and to apply, Freund's original formulation was also far too irritant in larger animals or humans. This was partly because Freund

\footnotetext{
"Anthony C. Allison has popularized the use of the term "formulation" for the composition of an adjuvant.
} 
had at his disposal only mineral oil containing hazardous unsaturated components.

In the sixty years since Freund's original work, modern medical paraffin oils have become available, relying on treatment with sulphuric acid. Emulsifiers too are now available in pharmaceutical quality. In this upgraded form, Freund's incomplete Adjuvant (IFA) has been used in well over a million human vaccinations. Freund's complete adjuvant (FCA) contains mycobacterial cell walls, which increase its effect but compromise its biocompatibility.

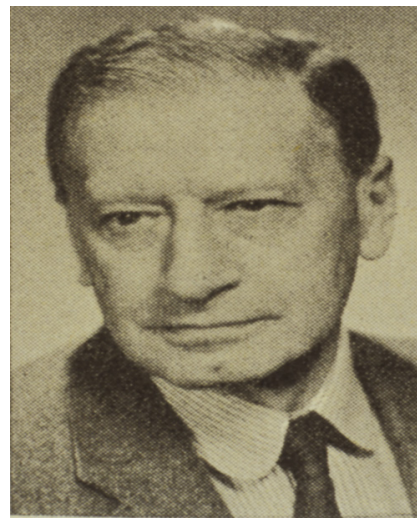

Jules Freund Jules

\section{MONTANIDE EMULSIONS}

Seppic /Air liquide has brought onto the market a multitude of improved Freund-type emulsions under the designation Montanide ISA, later also as oil-in-water emulsions [7].

A drop of Freund's oil containing the minidroplets of aqueous antigen can float stably on the surface of water. But upon gentle stirring on warm plasma it soon disperses in the liquid to form ultrafiltrable droplets of oil. Something similar seems to happen at the injection site in the host. So why not use oil-in-water emulsions in the first place?

\section{WOODARD'S OIL-IN-WATER EMULSIONS}

This is what Lynn Woodard [8] did at the University of Moscow (Idaho, USA) around 1980, paving the way to modern vaccine adjuvant technology. His work has been much used but was little recognized at the time.

He described emulsions of hexadecane and emulsifiers. In systematic studies he investigated the context of emulsion stability, composition and concentration with adjuvancy and clearly established the role of the adjuvant as a vaccine vehicle. He also redefined and clarified the function of amine compounds [9]. Since he never used any immunopotentiators, he could afford the exclusive use of mice in all his work. He did not himself propose commercial adjuvants.

The formulations which he used in his experiments have served as working standards for Gerbu over many years of development.

\section{MF59 OIL-IN-WATER ADJUVANT}

The first well accepted oil adjuvant for human vaccination was developed by Chiron-Novartis [10], clearly based on Woodard's concepts. It is worth showing how this formulation sprang from a huge amount of work and knowledge including all kinds of immunomodulators. Two groups joined forces to arrive at a final product of remarkable simplicity. In the process, all the "pseudo-adjuvants" initially used were thrown overboard in 1995. The two groups and their contributions were:

Synthex Palo Alto: Noelene E. Byars,

Deborah Lidgate, and Anthony C. Allison

Squalene, Tween 80, Threonyl-MDP,

Pluronic 121, Microfluidizer

Ciba-Geigy Basel: D.G. Braun, P. van Hogevest, and

G. Schumann

MDP-derivative, MTP-PEPhospholipids

Microencapsulation,

And the final result: Chiron-Novartis. MF59

Peter van Hogevest et al.

Squalene, Tween 80, Span 85,

Microfluidizer. Buffers.

MF59 features $0.2-\mu \mathrm{m}$-size droplets in buffer solution produced by means of a microfluidizer (MF) machine. Squalene replaces the hexadecane. This adjuvant is special in being the product of a vaccine manufacturer

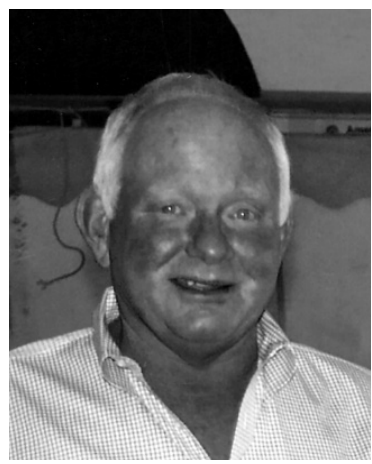

Lynn Woodard

\section{GERBU LIPID-IN-WATER ADJUVANT}

Similar to the MF59 story, the development started with GMDP, licensed to Gerbu by the Shemiakin Institute in Moscow. This is a highly sophisticated muramyl dipep-tide, extremely effective in mice at both cellular and humoral level and also believed to have excellent potential as a general use adjuvant. But there followed the usual disappointment: no serum antibody production in larger animals. So gradually we too have reverted to Lynn Woodard's world of emulsions.

An antigen dose of $300 \mu \mathrm{g}$ BSA per mouse was applied at the beginning. Many authors have used similar high antigen doses and have set a standard of FCA performance as $100 \%$ in general adjuvant research and development. With this dose it was quite easy to reach an antibody titre which evidently represented the top bioresponse capability of the immune system.

But is this really true? In fact it suffices to reduce the antigen dose to $10 \mu \mathrm{g}$ BSA / mouse and adjuvants stronger than FCA can be created quite easily (see Fig. 1). Likewise, many hundreds of rabbit tests have been carried out with 100 $\mu \mathrm{g}$ BSA per rabbit [11], equivalent to a dose of $1 \mu \mathrm{g}$ BSA per mouse.

Starting from Woodard's basis formulation (WBF) which consists of: hexadecane: 50\%, Tween 80: 35\%, Span 80: 
$15 \%$, a host of parameters in liquid or solid lipid ingredients have been investigated, the presence of emulsifiers and of charged lipids, anionic or cationic has been studied, also that of many buffer systems, potentiators and preservatives.

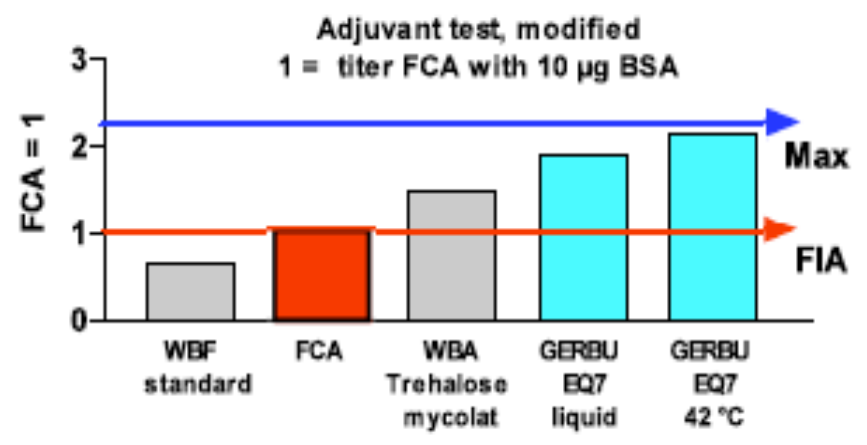

Fig. (1). Lipid composition. Many formulations are more efficient than Freund's.

As another example we show the impact of liquid drop size (see Fig. 2), which used to be a topic of experimental controversy.

\section{Adjuvant Particle Size}

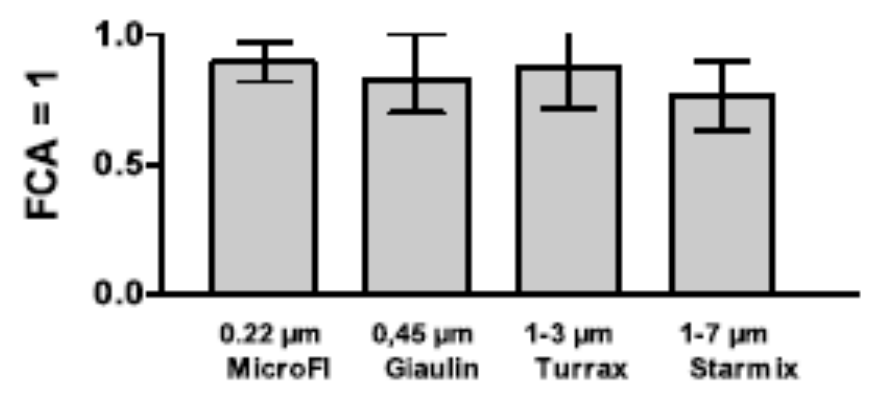

Fig. (2). Drop size versus adjuvant effectivity.

Within the range $0.2-5 \mu \mathrm{m}$ there is little variation, but 2 $\mu \mathrm{m}$ size particles, known as "stealth particles", are taken to be optimal.

In mice the presence of strong immunopotentiators has even induced the formation of (undesirable) hexameric IgM, but led to acceptable antibody levels cases where extremely low antigen doses were available.

Therefore GERBU Adjuvant MM has been developed with a special cocktail of stimulants including $d-$ polyadenylic-d-polyuridylic acid [12]. It is a product specially designed for making monoclonal antibodies.

After 4 years of systematic development, GERBU Adjuvant shows the following features $[13,14]$ with particle size $1-3 \mu \mathrm{m}$

1. Particles positively charged

2. Synergistic emulsifiers

3. Stabilization against particle coalescence

4. Storage stability of adjuvant

5. Storage stability of vaccine-adjuvant mix

6. Active and passive sterility

7. Economical price
The following varieties have been developed:

Gerbu Adjuvant 3022 for cow vaccines

Gerbu Adjuvant 3044 for chicken vaccines

Gerbu Pharma Adjuvant 3003 in phase I studies

\section{LEDERER'S IMMUNOMODULATORS}

Edgar Lederer's [15] contribution to adjuvant science cannot go unnoted. Studying the effect of the mycobacteria in Freund's complete adjuvant, he showed that lysozyme lysates of mycobacteria were just as effective as whole bacteria and he described the structure and synthesis from bacterial cell walls of muramyl-dipeptides (MDP) such as $\mathrm{N}$ acetylmuramyl-L-ala-D-isoglutamine; called Adjuvant Peptide. He also elucidated the structure of trehalose dimycolate (M. tuberculosis cord factor) and of Lipid A. In his study of the increase of antibody output he almost exclusively used mice for antibody monitoring. His whole life long Lederer failed to realize that it was not really Adjuvants to which he was devoting his efforts, but immunostimulators or immunomodulators [16] (such as his famous adjuvant peptide, 1990). But as a result, in animals the size of rabbits or bigger, all his fancy factors stopped working and no increase of serum antibody was seen. Never the less, his work has opened new fields of research on immune response and will remain fruitful in times to come.

Literally hundreds of research articles have appeared describing all sorts of liposome formulations, too numerous to mention. And still more work is going on with a multitude of immunostimulating factors, DNA vaccines, oligodeoxynucleotides, and cytokines. Who knows? One day perhaps a much milder and far more efficient "adjuvant" will become available for our vaccines, superseding all the coarse emulsions I have pictured here as "state of the art".

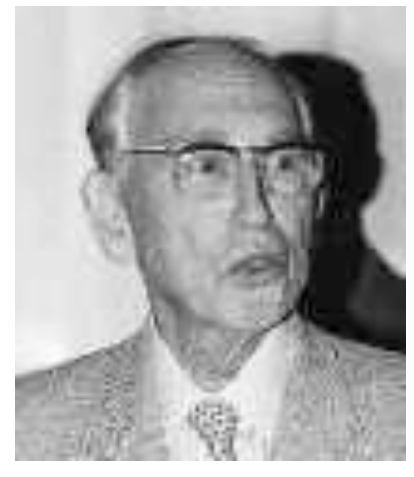

Edgar Lederer

\section{PRACTICAL VACCINE ADJUVANTS}

Medicines are defined as substances intended to influence the human or animal body. Official registration is required for their use. Does an adjuvant fall into this category, making it a medicine? The German legislation (AMG 2005, paragraph 2.5) offers no opinion, but the official commentary "Cloesel-Cyran" clearly classifies adjuvants as medicines.

Dramatic legal action concerning this question took place in 1994. Difco Laboratories and Gerbu Biotechnik GmbH were summoned to withdraw their products from the German market. A considerable outcry eventually resulted in a com- 
promise in which responsibility for experimental adjuvants was switched to the veterinary legislation, which only requires formal registration of any particular experiment.

Vaccine adjuvants were still classified as medical products. Gerbu has continued developing vaccine adjuvants with animal experiments outside Germany. Only on April 28th 2004, after many legal disputes with the regulatory authorities, did Gerbu receive official notification that an adjuvant is really not a medicine. It is only an auxiliary, like sugar or salt. Information on safety and efficiency has to be provided, and the adjuvanted vaccine must be clinically tested by its manufacturer in every new case. This represented the green light to further progress.

\section{ADJUVANTS IN PHARMACEUTICAL VACCINES}

The use of modern formulations is only at the very beginning, as seen from the present data. In Germany we have "Die Rote Liste", or "the red list", a thick book containing all official medicines giving details of their composition. In 2007 we find:

$\begin{array}{llr}\text { - } & \text { Total number of vaccines registered } & 69 \\ \text { - } & \text { Aluminium hydroxide or phosphate } & 21 \\ \text { - } & \text { MF59 (Novartis) } & 3 \\ \text { - } & \text { Lecithin (?) } & 2 \\ \text { - } & \text { No adjuvant } & 33\end{array}$

Genuinely new high-efficiency adjuvants are still waiting for their turn to appear in vaccines

\section{ADJVANTS IN VETERINARY VACCINES}

In contrast to pharmaceutical vaccines, there is a dearth of information about the properties and use of veterinary vaccines and less still about the incorporation of adjuvants. Although the famous Paul Ehrlich Institute for Sera and Vaccines has given very kind assistance, reliable recent data could not be obtained.

Due to the strong interest among vaccine producers, the use of alumina adjuvants in veterinary vaccines [17] has been documented [18] but is still far from the precise data we find in "Die Rote Liste".

\section{ANTIGEN MEETS ADJUVANT - WHEN AND WHERE ?}

An example we can offer is Gerbu Pharma Adjuvant (GPA), a Tocopherylacetate-Lecithin system, containing 2$\mu \mathrm{m}$-size particles, which are solid at $40^{\circ} \mathrm{C}$, cationized with cetylpyridyl ammonium chloride, optionally with GMDP. This GMDP addition should make it "better" according to everything we know, but the proof must await the results of clinical tests currently underway in India, Taiwan and Turkey.

\section{ADJUVANT COMPARISON CHEAPER VACCINES}

As shown in the figure below, only about $1 / 60$ of the expensive antigen is required.

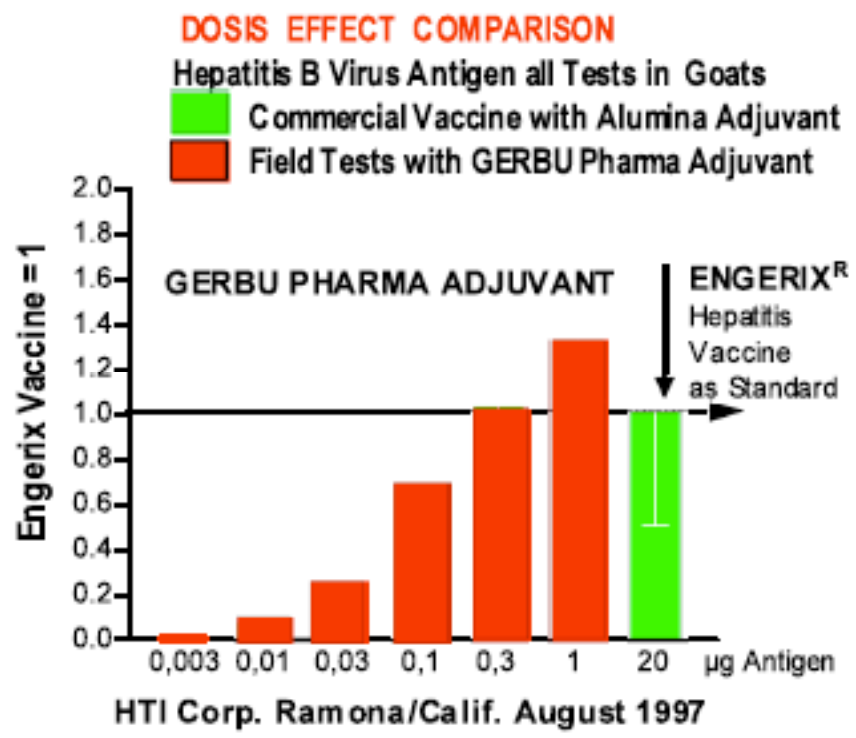

Fig. (3).

\section{ADJUVANT COMPARISON MORE EFFECTIVE VACCINES}

About a 10 times stronger effect is observed using identical doses of antigen:

\section{ADJUNANT EFFECT COMPARISON}

$20 \mu \mathrm{g}$ Hepatitis B Virus Antigen al Tests in Goats Commercial Vaccine with Alumina Adjuvant Field Tests with various Adjuvant

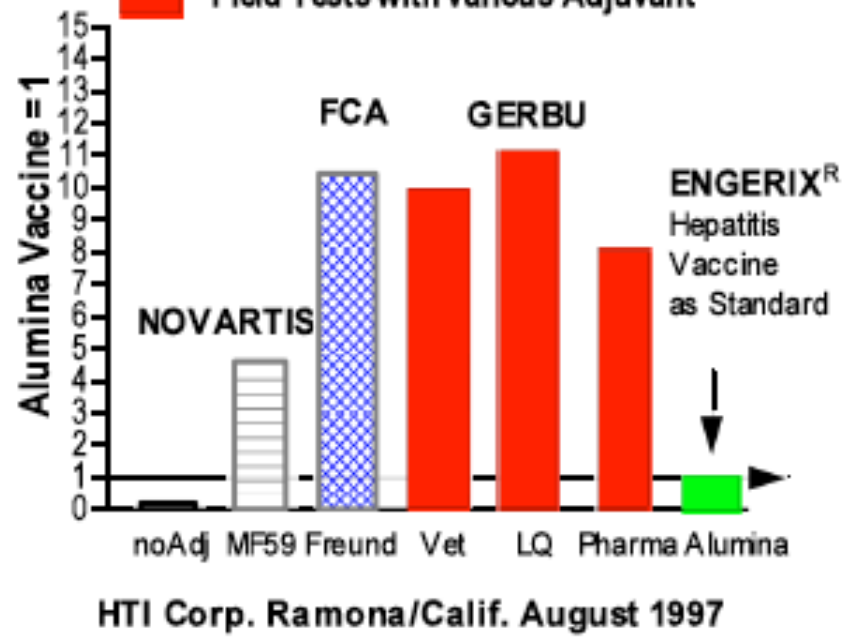

Fig. (4).

Source of previous two figures:

Field tests at HTI Inc, Ramona Cal. 1999.

Each column with three goats, 3 months.

\section{REFERENCES}

[1] Freund J. The mode of action of immunologic adjuvants. Adv Tuberc Res 1956; 7: 130-148.

[2] Glenny AT, Pape CG, Waddington H, Wallace W. The antigenic value of the toxin-antitoxin precipitate of Ramon. J Pathol Bacteriol 1926; 29: 31-40. 
[3] Merschheimer E, Küster E, Fischer W. Über die Fähigkeit des Tonerdepräparates B Diphtherie-Toxin zu binden. Ber Dtsch Chem Ges 1931; 64: 2174-2178.

[4] Rabinowitsch L. Zur Frage des Vorkommens von Tuberkelbazillen in Marktbutter. Z. f. Hygiene 1887; 26: 90-111.

[5] Grassberger G. Über die nach intraperitonealer Injektion von Marktbutter beim Meerschweinchen vorkommenden Veränderungen. Münchner Med Wschr 1899; 46: 382-385.

[6] Freund J. Antibody formation. J Immunol 1948; 60: 383-398.

[7] Aucouturier J, Dupuis I, Ganne V. Adjuvants designed for veterinary and human vaccines. Vaccine $2001 ; 19 ; 2666-2672$

[8] Woodard L, Jasman F. Stable oil-in-water emulsions, preparation and use as lipophilic adjuvants for vaccines. Vaccine 1985; 3: 137144.

[9] Woodard L. Adjuvant activity of water-immiscible surfactants. Lab Anim Sci 1989; 29: 222-225.

[10] Ott G, Barchfeld GE, Radakrishnan R, van Hogevest P, van Nest P. In: Powell MF, Newman MJ. Ed. Pharmaceutical Biotechnology. Vaccine Design: Design and evaluation of a safe and potent adjuvant for human vaccines, Plenum Press, New York and London 1995; 6: 277-296.
[11] Grubhofer N. An adjuvant formulation based on GMDP and DDA synergist. Immunol Lett 1995; 44: 19-24.

[12] Hovanessian AG. Galabru J, Rivière Y, Montagnier Luc. Efficiency of poly (A). poly(U) as an adjuvant. Immunol Today 1988; 33:161-162.

[13] Grubhofer N, inventor; Gerbu Biotechnijk GmbH assignee. Mittel zur Steigerung der Ausbeute von Antikörpern. Deutsches Patent DP 19511 236. 1999 Juni.

[14] Grubhofer N, inventor; Gerbu Biotechnik GmbH, assignee. Method for improving the yield of immunantibodies in vaccination of animals and humans. Unitetd States patent US 5019 466. 1998 July.

[15] Lederer E. Synthetic immunostimulants derived from the bacterial cell wall. J Med Chem 1980; 23: 820-825.

[16] Hadden JW. In Hadden JW. Ed. The Immunopharmacology of Immunotherapy: Advances in Immunopharmacology, Pergamon Press, London 1981; 336.

[17] Lindblad EB. Aluminium adjuvants - in retrospect and prospect. Vaccine 2004; 22: 3658-3668

[18] Lindblad EB. Aluminium adjuvants. In: Stuart-Tull DES. Ed. The Theory and Practical application of Adjuvants, John Wiley \& Sons Ltd, London, 1995; 21-35.

(C) Nikolaus A. Grubhofer; Licensee Bentham Open.

This is an open access article distributed under the terms of the Creative Commons Attribution License (http://creativecommons.org/license/by/2.5/), which permits unrestrictive use, distribution, and reproduction in any medium, provided the original work is properly cited. 